\title{
MALIGNANCY IN THYROID NODULES- A RETROSPECTIVE ANALYSIS
}

\author{
Erugurala Mahendar'1, T. R. Ravimohan ${ }^{2}$
}

${ }_{1}^{1}$ Assistant Professor, Department of Plastic Surgery, Gandhi Medical College, Hyderabad, Telangana, India. ${ }^{2}$ Associate Professor, Department of General Surgery, Kakatiya Medical College, Warangal, Telangana, India.

\begin{abstract}
BACKGROUND
Thyroid cancer is a relatively uncommon malignancy accounting for less than $1 \%$ of all new malignancies. It is a slowly progressing disease and has an overall favourable outcome with only $9 \%$ of patients dying from it. The relatively indolent nature of thyroid malignancy is generally ascribed to the innocuous biological behaviour that is characteristic of these neoplasms. Among the various types of thyroid cancers, papillary carcinoma is the most common form followed by follicular and medullary carcinoma. Of all the thyroid carcinomas, papillary carcinoma has better prognosis. Anaplastic thyroid carcinoma usually assumes an aggressive course and is rapidly lethal, carrying the poorest prognosis of all. Most patients present with a palpable swelling in the neck which initiates assessment through a combination of history, physical examination, and FNA biopsy.
\end{abstract} ABSTRACT

\section{MATERIALS AND METHODS}

This is a retrospective study of 50 cases of primary malignant tumours of thyroid diagnosed and treated in Osmania General Hospital and MNJ institute of oncology between June 2008 and November 2010

\section{RESULTS}

The mean age of thyroid malignancy was 35.46 years with a female preponderance. $70 \%$ of the patients had papillary carcinoma followed by follicular carcinoma in $24 \%$, Hurthle cell variant in $4 \%$ and lymphoma in the rest. Most of the cases (56\%) had presented with solitary thyroid nodule and a history of duration between one to two years in 17 patients. Cervical lymph node enlargement was found in $17.14 \%$ of patients with papillary carcinoma.

\section{CONCLUSION}

Thyroid cancer is a common endocrine neoplasm which can occur most commonly between age groups of 21-65 years. Women are frequently affected. Usual mode of presentation is solitary thyroid enlargement with papillary carcinoma as the common type. Lymphatic spread is common with papillary carcinomas.

\section{KEY WORDS}

Thyroid Malignancy, Papillary Carcinoma, Follicular Carcinoma, Solitary Thyroid Nodule. Ultrasonography, Fine Needle Aspiration Cytology.

HOW TO CITE THIS ARTICLE: Mahendar E, Ravimohan TR. Malignancy in thyroid nodules- a retrospective analysis. J. Evolution Med. Dent. Sci. 2018;7(46):4986-4989, DOI: $10.14260 /$ jemds/2018/1109

\section{BACKGROUND}

Thyroid nodules are a common clinical finding, with an estimated prevalence on the basis of palpation that ranges from $3 \%$ to $7 \% 1,2$ and with the increasing use of ultrasound for unrelated problems are detected with greater frequency. ${ }^{3}$ The prevalence of palpable thyroid nodule in South India is about $12.2 \%$. However, the reported incidence of thyroid cancer in general population is low, being only about $1 \%$. Thyroid cancers occur in approximately $5 \%$ of all thyroid nodules independent of their size. ${ }^{3}$

The incidence of thyroid malignancy is increasing over the years. Both solitary nodules and multinodular goiters are associated with malignancy. some studies implied that the incidence of malignancy may be higher for solitary nodules than for multiple nodules.5,6 Multinodularity detected by USG does not necessarily exclude malignancy. ${ }^{7}$

'Financial or Other Competing Interest': None.

Submission 01-10-2018, Peer Review 25-10-2018,

Acceptance 31-10-2018, Published 12-11-2018.

Corresponding Author:

Dr. T. R. Ravimohan,

6-1-294/8, Street No. 2,

Padmaraonagar, Secunderabad-500025,

Telangana, India.

E-mail: ravimohantr@gmail.com

DOI: $10.14260 /$ jemds $/ 2018 / 1109$
The use of high-resolution ultrasonography (US), sensitive thyrotropin (TSH) assay, and fine-needle aspiration (FNA) biopsy is the basis for management of thyroid nodules. ${ }^{8}$

High-resolution US is the most sensitive test available to detect thyroid lesions, measure their dimensions, identify their structure, and evaluate diffuse changes in the thyroid gland.9,10 Hypoechogenicity, microcalcifications, irregular or microlobulated margins, taller-than-wide shape, and increased intranodular vascularity are risk factors for malignancy, 11 , The presence of intrinsic microcalcification seems the most reliable criterion on which increased suspicion for malignancy in thyroid nodules.12,13,14 Intranodular blood flow can be detected in a greater percentage of malignant nodules. ${ }^{15,16}$

Clinical management of thyroid nodules should be guided by the combination of US evaluation and FNA biopsy. ${ }^{17}$ FNA biopsy is currently the best triage test for the preoperative evaluation of thyroid nodules. ${ }^{18}$ Any solitary or dominant thyroid nodule larger than $1 \mathrm{~cm}$ should be evaluated by FNA cytology, unless proven to be hyperfunctioning. Micronodules need to be evaluated by cytology only in the event of suspicious finding at US (Solid hypoechoic with microcalcifications) or personal history. ${ }^{19}$

Since FNA is considered to be most accurate and costeffective in the preoperative investigation of thyroid nodules, 
it is accepted as "gold standard" in the management of thyroid nodules. ${ }^{19,20,21}$ The use of FNAC has reduced the number of patients with solitary thyroid nodule undergoing unnecessary surgery and has led to proper planning of surgery in malignant cases. If US guidance is used instead of palpation, the value of FNA diagnostic accuracy enhances. ${ }^{22-25}$ US helps direct the needle tip to the desired site, avoiding vessels in close vicinity to the nodule or areas of central necrosis, which often yield nondiagnostic specimens. ${ }^{26}$ The presence of more than one suspicious feature in US image of thyroid nodule should be considered as an indication for repeat FNA.

The preoperative evaluation of thyroid nodules to distinguish between benign and malignant nodules is very important. It helps to avoid unnecessary extensive surgery and potential surgery related adverse effects, such as hypothyroidism, hypocalcaemia, and recurrent laryngeal nerve injury.

\section{MATERIALS AND METHODS}

This is a retrospective study of 50 cases of primary malignant tumours of thyroid diagnosed and treated in Osmania General Hospital and MNJ institute of oncology between June 2008 and November 2010.

The present study was done in a tertiary care center of South India. The study was based on the review of case records of 50 patients who were operated for thyroid nodule. It included only those cases where a postoperative histopathological conformation of malignancy was obtained in STN and also multinodular goiter who had undergone thyroidectomy between June 2008 and November 2010 .

Those with benign histopathology proven after surgery were excluded from study.

An informed consent was taken from the patients and their relatives to use the information for publication purpose. The study was approved by institutional ethics committee.

Most of the patients presented directly to the outpatient departments of $\mathrm{OGH}$ or $\mathrm{MNJ}$ and some were referred from Endocrinology department.

For all patients the following data were recorded: Age, gender, history of radiation exposure, family history of thyroid disease, and the thyroid hormone profile. The operative procedure was based on the different parameters like age of the patients, clinical examination, fine-needle aspiration cytology (FNAC) findings, USG interpretation, and indirect laryngoscopy. The decision for surgery was based on individual patient's examination and investigation findings.

In most of the patients, the plan of surgery was decided beforehand. If it was a STN, diagnosed clinically as well as ultrasonographically, hemi-thyroidectomy of the involved side was done, and the specimen was sent either for frozen section or for routine histopathological examination (HPE). In the event of a malignant frozen section report, completion thyroidectomy was done in the same sitting, whereas in inconclusive frozen section, we preferred to wait till the final histopathology report. The decision for other procedures like total thyroidectomy, total thyroidectomy with central neck dissection, total thyroidectomy with selective neck dissection, total thyroidectomy with modified radical neck dissection was based on the clinical, radiological, FNAC and histopathology findings.
During surgery, the site and type of incision were decided. Hemostasis, safeguarding of the recurrent laryngeal nerve, parathyroid, and other vital structures was taken care of during the dissection. Appropriate measures were taken to correct postoperative hypocalcemia and anemia and the drain was taken care of. Hypocalcemic features were managed with supplementation of calcium and Vitamin D. If the final histopathology report was either follicular or papillary carcinoma, the patients were advised to undergo I131 whole body scan, preferably within 4-6 weeks after surgery and radioactive iodine ablation was advised for residual tissue in the thyroid bed. All the patients were advised regular follow-up.

Case records of the patients revealed that all the patients had a thorough clinical examination of the swelling and examination of neck for any cervical lymph nodes.

Indirect laryngoscopy was done in all prior to surgery.

All of them had undergone ultrasound of thyroid gland, fine needle aspiration cytology. Thyroid scinti scan with TC99m pyrophosphate was done in a few patients.

In all the patients, thyroid function tests were done. Serum calcitonin was estimated in patients with Medullary carcinoma. Also, serum calcium and phosphate levels were evaluated in selected patients to rule out coexisting Hyperparathyroidism.

\section{RESULTS}

The age of 50 patients ranged between 15 to 65 years with a mean of 35.46 years. Though most of patients were in age group 21-30 years, 23 out of 50 selected cases, thyroid cancer was not noted in this group of patients.

Majority of the patients, 41 out of 50, were female. Female to male ratio was $4.5: 1$.

Duration of history in this study ranged from 6 months to 5 years. Duration of 5 years and more was noted in cases where malignancy was observed in multinodular goiter.

Initial mode of presentation in majority ( 28 of 50 ), 56\% was as solitary thyroid nodule. 22 patients (44\%) presented with multinodular goiter.

None of the patients presented with occult thyroid carcinoma. Five patients had biochemical evidence of hypothyroidism.

Majority of the patients had papillary carcinoma thyroid (70\%). Next most common type was follicular carcinoma (24\%). Two patients had Hurthle cell carcinoma (4\%), and one patient had lymphoma of thyroid.

Cervical lymph nodal enlargement of levels III, IV, V, was found in 5 out of 50 patients

There was no evidence of distant metastasis.

Lymph nodal metastasis was observed in $17.14 \%$ of patients who had papillary carcinoma of thyroid.

\begin{tabular}{|c|c|c|c|}
\hline Serial Number & Age Group & No. of Cases & Percentage \\
\hline 1 & $11-20$ & 4 & 8 \\
\hline 2 & $21-30$ & 23 & 46 \\
\hline 3 & $31-40$ & 10 & 20 \\
\hline 4 & $41-50$ & 5 & 10 \\
\hline 5 & $51-60$ & 7 & 14 \\
\hline 6 & $61-70$ & 7 & 14 \\
\hline 7 & 71-80 & 0 & 0 \\
\hline \multicolumn{2}{|c|}{ Total } & 50 & \\
\hline \multicolumn{4}{|c|}{ Table I. Age Distribution of Thyroid Malignancy } \\
\hline
\end{tabular}




\begin{tabular}{|c|c|c|}
\hline Sex & Number of Patients & Percentage \\
\hline Male & 9 & 18 \\
\hline Female & 41 & 82 \\
\hline \multicolumn{2}{|c|}{ Table II. Sex Distribution of Malignancy } \\
\hline
\end{tabular}

\begin{tabular}{|c|c|c|}
\hline Type of Thyroid Cancer & Number of Cases & Percentage \\
\hline Papillary carcinoma & 35 & 70 \\
\hline Follicular carcinoma & 12 & 24 \\
\hline Hurthle cell carcinoma & 2 & 4 \\
\hline lymphoma & 1 & 0.5 \\
\hline
\end{tabular}

\begin{tabular}{|c|c|c|}
\hline Clinical Presentation & Number of Patients & Percentage \\
\hline Solitary thyroid nodule & 28 & 56 \\
\hline Multinodular goiter & 22 & 44 \\
\hline \multicolumn{2}{|c|}{ Table IV. Initial Mode of Presentation } \\
\hline
\end{tabular}

\begin{tabular}{|c|c|c|c|}
\hline $\begin{array}{c}\text { Type of Thyroid } \\
\text { Cancer }\end{array}$ & $\begin{array}{c}\text { Present } \\
\text { Study }\end{array}$ & $\begin{array}{c}\text { Misra } \\
\text { et al }\end{array}$ & $\begin{array}{c}\text { Hoffmnn } \\
\text { et al }\end{array}$ \\
\hline Papillary carcinoma & $70 \%$ & $62 \%$ & $82.2 \%$ \\
\hline Follicular carcinoma & $24 \%$ & $17 \%$ & $4.4 \%$ \\
\hline Hurthle cell carcinoma & $4 \%$ & 0 & 0 \\
\hline lymphoma & $0.5 \%$ & 0 & 0 \\
\hline Medullary carcinoma & 0 & $8 \%$ & $6.7 \%$ \\
\hline Anaplastic carcinoma & 0 & $10 \%$ & $6.7 \%$ \\
\hline Table V. Relative Incidence of Thyroid Cancers in Other \\
Studies \\
\hline
\end{tabular}

\section{DISCUSSION}

In this study, majority of the patients were in the age group of 21-30 years. No cases were recorded in ages less than 10 and above 65 years.

The incidence of malignancy was fond to increase with every decade till 60-70 years age group. These results are consistent with findings of the study conducted by Misra et al. 27

We have noted that female gender $82 \%$ was associated with high risk of malignancy as was the observations made by Misra et al where female patients were $63 \%$.

Micro calcification, solid echogenicity of the nodule, and presence of cervical lymphadenopathy was significantly associated with malignancy.

Fine-needle aspiration cytology is a recommended procedure in the initial assessment and management of thyroid nodules and is also cost-effective. In this study every patient with a palpable thyroid nodule underwent fine-needle aspiration cytology. Ultrasonography guided fine-needle aspiration cytology is superior to conventional method and can help lower the occurrence of non-diagnostic smears. There is a better yield of diagnostic cytological material with the help of the ultrasonography guided aspirations compared to blind fine-needle aspiration cytology.

The decision and plan of surgery in each patient was taken after the results of fine-needle aspiration cytology and ultrasonography features of the nodules. When fine-needle aspiration cytology report was malignant, total thyroidectomy was done.

The management of thyroid nodules requires a combination of clinical evaluation followed by appropriate investigations. An individualized approach is increasingly becoming relevant in the management of thyroid nodules.
Papillary carcinoma was the common thyroid malignancy in this study which constituted about $70 \%$ of the cases. The incidence of this malignancy was $62 \%$ in the study conducted by Misra et al and $82.2 \%$ in the study of Hoffmann et al. ${ }^{28}$ The results of this study are comparable to both.

Follicular carcinoma was the next most common type observed in $24 \%$ of the patients. This is comparable to the results of the study conducted by Misra et al where it was $17 \%$. Follicular carcinoma constituted only $4.4 \%$ in the study if Hoffmann et al.

There was one patient $(0.5 \%)$ who had lymphoma in this study.

In those cases where postoperative HPE was reported as malignant either in frozen or by paraffin section, completion thyroidectomy of the remaining lobe was done. Total thyroidectomy was done in those cases where FNAC was reported as malignant.

The initial mode of presentation in this study was in the form of solitary thyroid nodule in $56 \%$ of the patients. The same was the mode of presentation in the study of Misra et al in $68.2 \%$ of the patients.

Multinodular goiter was the presentation in $44 \%$ of the patients in this study which was $11.4 \%$ in the study of Misra et al.

There were five patients who had hypothyroidism in association with thyroid malignancy in this study.

The incidence of cervical lymph node involvement was $10 \%$ in this study which is almost similar to that observed by Misra et al (9.8\%)

Decision of neck dissection was taken in those cases with either palpable lymph nodes in the neck or USG finding suggestive of lymphadenopathy.

The result of our study shows that the incidence of malignancy in STNs is indeed high. Multinodularity detected by USG does not necessarily exclude malignancy.

Thyroid cancer though uncommon compared to other malignancies, is a common endocrine neoplasms accounting for a significant number of cases diagnosed each year.

Thyroid cancer can occur over a wide range of age but is usually observed in the age between $21-65$ years. Women are more commonly affected by thyroid cancer than men.

Papillary carcinoma is the commonest and frequent of all the thyroid malignancies. Follicular carcinoma is the second common type of malignancy.

The initial mode of presentation is usually as solitary thyroid nodule. Lymphatic spread was common with papillary thyroid carcinoma.

\section{CONCLUSION}

Incidence of malignancy in STNs is indeed high. Multinodularity detected by USG does not necessarily exclude malignancy.

Thyroid cancer though uncommon compared to other malignancies, is a common endocrine neoplasms accounting for a significant number of cases diagnosed each year.

Thyroid cancer can occur over a wide range of age but is usually observed in the age between 21-65 years. Women are more commonly affected by thyroid cancer than men.

Papillary carcinoma is the commonest and frequent of all the thyroid malignancies. Follicular carcinoma is the second most common type of malignancy. 
The initial mode of presentation is usually as solitary thyroid nodule. Lymphatic spread was common with papillary thyroid carcinoma.

\section{REFERENCES}

[1] Tunbridge WM, Evered DC, Hall R, et al. The spectrum of thyroid disease in a community: the Whickham survey. Clin Endocrinol (Oxf) 1977;7(6):481-93.

[2] Hegedüs L. Clinical practice. The thyroid nodule. N Engl J Med 2004;351(17):1764-71.

[3] Yeung MJ, Serpell JW. Management of the solitary thyroid nodule. Oncologist 2008;13(2):105-12.

[4] Unnikrishnan AG, Kalra S, Baruah M, et al. Endocrine Society of India management guidelines for patients with thyroid nodules: a position statement. Indian J Endocrinol Metab 2011;15(1):2-8.

[5] Tai JD, Yang JL, Wu SC, et al. Risk factors for malignancy in patients with solitary thyroid nodules and their impact on the management. J Cancer Res Ther 2012;8(3):379-83.

[6] Gupta M, Gupta S, Gupta VB. Correlation of fine needle aspiration cytology with histopathology in the diagnosis of solitary thyroid nodule. J Thyroid Res 2010;2010:379051.

[7] Gharib H, Papini E, Paschke R, et al. American Association of Clinical Endocrinologists, Associazione Medici Endocrinologi, and European Thyroid Association Medical guidelines for clinical practice for the diagnosis and management of thyroid nodules: executive summary of recommendations. Endocr Pract 2010;16(3):468-75.

[8] Gharib H, Papini E. Thyroid nodules: clinical importance, assessment, and treatment. Endocrinol Metab Clin North Am 2007;36(3):707-35.

[9] Baskin HJ. Ultrasound of thyroid nodules. In: Baskin HJ, ed. Thyroid ultrasound and ultrasound-guided FNA biopsy. Boston, MA: Kluwer Academic Publishers 2000:71-86.

[10] Solbiati L, Osti V, Cova L, et al. Ultrasound of thyroid, parathyroid glands and neck lymph nodes. Eur Radiol 2001;11(12):2411-24.

[11] Moon WJ, Baek JH, Jung SL, et al. Ultrasonography and the ultrasound-based management of thyroid nodules: consensus statement and recommendations. Korean J Radiol 2011;12(1):1-14.

[12] Hagag P, Strauss S, Weiss M. Role of ultrasound-guided fine-needle aspiration biopsy in evaluation of nonpalpable thyroid nodules. Thyroid 1998;8(11):989-95.

[13] Iannuccilli JD, Cronan JJ, Monchik JM. Risk for malignancy of thyroid nodules as assessed by sonographic criteria: the need for biopsy. J Ultrasound Med 2004;23(11):1455-64.
[14] Kakkos SK, Scopa CD, Chalmoukis AK, et al. Relative risk of cancer in sonographically detected thyroid nodules with calcifications. J Clin Ultrasound 2000;28(7):347-52.

[15] Levine RA. Something old and something new: a brief history of thyroid ultrasound technology. Endocr Pract 2004;10(3):227-33.

[16] Hegedüs L. Thyroid ultrasound. Endocrinol Metab Clin North Am 2001;30(2):339-60.

[17] Gharib H, Papini E. Thyroid nodules: clinical importance, assessment, and treatment. Endocrinol Metab Clin North Am 2007;36(3):707-35.

[18] Wu HH, Jones JN, Osman J. Fine-needle aspiration cytology of the thyroid: ten years-experience in a community teaching hospital. Diagn Cytopathol 2006;34(2):93-6.

[19] Pacini F, Schlumberger M, Dralle H, et al. European consensus for the management of patients with differentiated thyroid carcinoma of the follicular epithelium. Eur J Endocrinol 2006;154(6):787-803.

[20] Castro MR, Gharib H. Thyroid fine-needle aspiration biopsy: progress, practice, and pitfalls. Endocr Pract 2003;9(2):128-36.

[21] Cooper DS, Doherty GM, Haugen BR, et al. Revised American Thyroid Association management guidelines for patients with thyroid nodules and differentiated thyroid cancer. Thyroid 2009;19(11):1167-214.

[22] Cesur M, Corapcioglu D, Bulut S, et al. Comparison of palpation-guided fine-needle aspiration biopsy to ultrasound-guided fine-needle aspiration biopsy in the evaluation of thyroid nodules. Thyroid 2006;16(6):555-61.

[23] Rosen IB, Provias JP, Walfish PG. Pathologic nature of cystic thyroid nodules selected for surgery by needle aspiration biopsy. Surgery 1986;100(4):606-13.

[24] Danese D, Sciacchitano S, Farsetti A, et al. Diagnostic accuracy of conventional versus sonography-guided fine-needle aspiration biopsy of thyroid nodules. Thyroid 1998;8(1):15-21.

[25] Carmeci C, Jeffrey RB, McDougall IR, et al. Ultrasoundguided fine-needle aspiration biopsy of thyroid masses. Thyroid 1998;8(4):283-9.

[26] Baskin HJ. Ultrasound-guided fine-needle aspiration biopsy of thyroid nodules and multinodular goiters. Endocr Pract 2004;10(3):242-5.

[27] Saroj MK. A monograph on thyroid cancer. Japan International Cooperation Society 1994.

[28] Hoffman E. Carcinoma of thyroid: review of 304 cases. South Med J 1987:80(6);741-52. 